\title{
Influence of Stacking Sequence on the Mechanical and Dynamic Mechanical Properties of Cotton/Glass Fiber Reinforced Polyester Composites
}

\author{
Emanoel Henrique Portella ${ }^{a}$, Daiane Romanzini ${ }^{b * *}$, Clarissa Coussirat Angrizani ${ }^{b}$,
}

Sandro Campos Amico ${ }^{b}$, Ademir José Zattera ${ }^{a}$

${ }^{a}$ Postgraduate Program in Process and Technology Engineering - PGEPROTEC, University of Caxias do Sul - UCS, R. Francisco Getúlio Vargas, 1130, 95070-560, Caxias do Sul, RS, Brazil ${ }^{b}$ Postgraduate Program in Mining, Metallurgical and Materials Engineering - PPGEM, Federal University of Rio Grande do Sul-UFRGS, Av. Bento Gonçalves, 9500, 91501-970, Porto Alegre, RS, Brazil

Received: January 25, 2016; Accepted: March 7, 2016

\begin{abstract}
This study focuses on the use of waste cotton fiber from the textile industry to produce composites with unsaturated polyester and to evaluate the performance of glass $(\mathrm{G})$ / cotton (C) fiber laminates, particularly their mechanical and dynamic mechanical properties. Distinct stacking sequences were studied but the overall fiber content was kept constant. In general, hybrid laminates exhibited intermediate mechanical properties compared to those of the pure laminates, and optimum performance was obtained when the glass fiber mats were placed on the surfaces of the composite. Furthermore, some hybrid laminates exhibited superior dynamic mechanical performance, even compared to the pure glass laminate. Lower tan delta peak height (related to better fiber-matrix interaction) values and higher $\mathrm{T}_{\mathrm{g}}$ were reported for the $[\mathrm{C} / \mathrm{G} / \overline{\mathrm{G}}] \mathrm{s}$ and $[\mathrm{G} / \mathrm{C} / \overline{\mathrm{C}}] \mathrm{s}$ samples which, together with the $[\mathrm{G} / \mathrm{C} / \overline{\mathrm{G}}] \mathrm{s}$ sample, exhibited the best results for reinforcement effectiveness and loss modulus peak height. Therefore, it is found possible to partially replace the glass fiber by waste cotton fiber considering that the final product may be optimized for mechanical property, which requires glass fiber at the surface of the laminate, or for dynamic mechanical properties, that allows higher cotton fiber content.
\end{abstract}

Key-words: Hybrid laminates, Dynamic mechanical analysis, Cotton fiber, Stacking sequence

\section{Introduction}

Composite materials, especially those with a polymeric matrix, are of considerable interest to researchers and engineers due to a wide range of combinations in material properties 1. In particular, the use of natural fibers, such as sisal, jute, curaua, ramie and cotton, in polymer composites has grown in recent years, due to material abundance, low cost and low density, and due to their renewable characteristics. These materials are also less abrasive to processing equipment compared to synthetic fibers, which becomes very important when equipment costs are high ${ }^{1-3}$.

Major advantages of synthetic fibers over natural fibers include lower moisture absorption of the former and their better adhesion with the polymer matrix ${ }^{4}$. An important drawback preventing wider exploitation of natural fibers is their hydrophilic character, which is incompatible with the hydrophobic character of the polymer matrix. Because of that, poor fiber/matrix interfacial adhesion is observed ${ }^{2,5}$.

Cotton fibers are usually found as waste from the textile industry, being usually deposited in landfills and dumps. Although cotton does not have high mechanical properties compared to similar fibers, it can be combined to polymers to yield composites with some mechanical properties superior to that of a pure polymer ${ }^{3}$ Borsoi et al. ${ }^{3}$ studied the incorporation of cotton fiber in thermoplastic matrix composites and obtained satisfactory mechanical results, including higher

*e-mail: dairomanzini@ibest.com.br impact and flexural strength as well as increased flexural modulus. Hashmi et al., ${ }^{6}$ studied cotton/unsaturated polyester composites and reported an improvement in structural integrity of the material under sliding wear conditions, a decreased specific wear rate and a higher coefficient of friction with the addition of the fiber.

Dynamic mechanical analysis (DMA) is widely used to characterize polymers and sometimes employed to investigate the relationship between macroscopic and microscopic material properties, corroborating mechanical characterization studies. For composites, DMA has been applied to understand the storage and loss moduli variation upon fiber incorporation. The glass transition temperature and the effectiveness $\mathrm{C}$ coefficient can also be estimated ${ }^{7,8}$.

The primary goal of this study is to evaluate the effect of the stacking sequence on the mechanical and the dynamic-mechanical properties of cotton/glass fiber reinforced polyester laminates, and to assess the amount of glass fibers that can be replaced without compromising of the evaluated properties.

\section{Materials and Methods}

\subsection{Materials}

The cotton fibers (waste from the textile industry) were supplied by H. Milagre (RS, Brasil). The glass fibers were supplied by Owens Corning (SP, Brazil). The orthophthalic 
unsaturated polyester resin Arazyn 13.0 was supplied by Ashland S/A(SP, Brazil). The initiator methyl-ethyl-ketone peroxide in diisobutyl phthalate (Butanox LPT) and the curing promoter dimethylaniline (DMA) were purchased from Disfibra (RS, Brazil).

\subsection{Methods}

The cotton fibers were chopped ( $25 \mathrm{~mm}$ length), dried for $30 \mathrm{~min}$ at $90^{\circ} \mathrm{C}$ in an oven with air circulation and randomly distributed in a pre-mold to produce a mat. Five layers of cotton fiber mat $(\mathrm{C})$ or glass fiber mat $(\mathrm{G})$ were stacked following different lay-up sequences (Table 1). Each layer accounted for $20 \%$ of the available fiber volume fraction, and the overall fiber content within the composite was kept constant at $30 \mathrm{vol} . \%$.

The resin was mixed with $0.1 \mathrm{wt} \%$ DMA and $1 \mathrm{wt} \%$ Butanox LPT and poured onto the fiber mats previously placed in a steel mold (dimensions: $170 \times 170 \times 3 \mathrm{~mm}^{3}$ ). Hot compression molding was carried out at $80{ }^{\circ} \mathrm{C}$ for $60 \mathrm{~min}$ under 4 ton. After that, pressure was released and post-curing was performed at $80{ }^{\circ} \mathrm{C}$ for $90 \mathrm{~min}$.

Fiber characterization was performed using thermogravimetric analysis (TGA - Shimadzu TGA-50) at a heating rate of $10^{\circ} \mathrm{C} \cdot \mathrm{min}^{-1}$, from 25 to $800^{\circ} \mathrm{C}$. The fibers were also investigated using Fourier transform infrared spectroscopy (FTIR - Nicolet IS10 - Thermo Scientific) with attenuated total reflectance (ATR).

Unnotched Izod impact tests were performed on laminate specimens (dimensions: $63.5 \times 12.7 \times 3 \mathrm{~mm}^{3}$ ) using a CEAST impact machine in accordance with ASTM D256. The pendulum contacts the sample at a constant distance $(22 \pm 0.05 \mathrm{~mm})$ from the specimen clamping point, at its centerline. The maximum hammer energy was $7.5 \mathrm{~J}$ and the average value obtained for 10 specimens for each laminate is reported. Flexural tests were performed in accordance with ASTM D790 using an EMIC DL-3000 universal testing machine $(2 \mathrm{kN}$ load cell) with 7 specimens (dimensions: $120 \times 12.7 \times 3 \mathrm{~mm}^{3}$ ) for each laminate.

The dynamic mechanical characteristics of the laminates were evaluated using a DMA 2980 Dynamic Mechanical Analyzer. One sample for each laminate (dimensions: $60 \times 10 \times 3 \mathrm{~mm}^{3}$ ) were heated from room temperature to $180^{\circ} \mathrm{C}$ at a heating rate of $3{ }^{\circ} \mathrm{C} / \mathrm{min}$, under three-point bending loading, at

Table 1. Nomenclature used for the different lay-up sequences and the relative volume fraction of cotton and glass fiber (constant overall fiber content of $30 \mathrm{vol} . \%)$.

\begin{tabular}{cccc}
\hline Nomenclature & $\begin{array}{c}\text { Lay-up } \\
\text { sequence }\end{array}$ & $\begin{array}{c}\% \mathbf{V}_{\mathbf{C}} \\
\text { (cotton } \\
\text { fiber) }\end{array}$ & $\begin{array}{c}\mathbf{\%}_{\mathbf{G}} \\
\text { (glass fiber) }\end{array}$ \\
\hline$[\mathrm{C}]_{5}$ & CCCCC & 100 & 0 \\
{$\left[\mathrm{C}_{2} / \overline{\mathrm{G}}\right] \mathrm{s}$} & CCGCC & 80 & 20 \\
{$[\mathrm{C} / \mathrm{G} / \overline{\mathrm{C}}] \mathrm{s}$} & CGCGC & 60 & 40 \\
{$[\mathrm{G} / \mathrm{C} / \overline{\mathrm{C}}] \mathrm{s}$} & $\mathrm{GCCCG}$ & 60 & 40 \\
{$[\mathrm{G} / \mathrm{C} / \overline{\mathrm{G}}] \mathrm{s}$} & $\mathrm{GCGCG}$ & 40 & 60 \\
{$[\mathrm{C} / \mathrm{G} / \overline{\mathrm{G}}] \mathrm{s}$} & $\mathrm{CGGGC}$ & 40 & 60 \\
{$[\mathrm{G} / \overline{\mathrm{C}}] \mathrm{s}$} & GGCGG & 20 & 80 \\
{$[\mathrm{G}]_{5}$} & GGGGG & 0 & 100 \\
\hline
\end{tabular}

$1 \mathrm{~Hz}$ frequency and an oscillation amplitude of $15 \mu \mathrm{m}$. The effectiveness C coefficient was calculated using Eq. (1) ${ }^{8}$.

$\mathrm{C}=\frac{\left(E_{g}^{\prime}-E_{r}^{\prime}\right)_{\text {composite }}}{\left(E_{g}^{\prime}-E_{r}^{\prime}\right)_{\text {resin }}}$

where: $E_{g}^{\prime}$ and $E_{g}^{\prime}$ are the storage modulus values in the glassy $\left(40^{\circ} \mathrm{C}\right)$ and rubbery $\left(160^{\circ} \mathrm{C}\right)$ regions, respectively.

\section{Results and Discussion}

\subsection{Cotton fiber characterization}

The results obtained from thermogravimetric analysis (TGA) of the cotton fibers are shown in Figure 1. The initial weight loss observed between 30 and $110{ }^{\circ} \mathrm{C}$ is attributed to the vaporization of water and some components that are physically attached to the fibers. The second weight loss process associated with the maximum decomposition rate at $348{ }^{\circ} \mathrm{C}$ is related to the degradation of the cellulose in the fiber. An extra weight loss process is sometimes observed in some natural fibers in the $220-310{ }^{\circ} \mathrm{C}$ range related to the presence of hemicellulose, but this was not identified in the DTG of the cotton probably due to the low amount of hemicellulose present in this fiber ${ }^{9-11}$. According to Satyanarayana et al. ${ }^{9}$, the composition of cotton is $\sim 90 \%$ cellulose, $\sim 6 \%$ hemicellulose, and $4 \%$ extractives, lignin and waxes.

Figure 2 shows the ATR-FTIR spectrum of the cotton fiber and typical bands of cellulose, lignin and hemicellulose are observed. The strong peak observed at $3330 \mathrm{~cm}^{-1}$ is

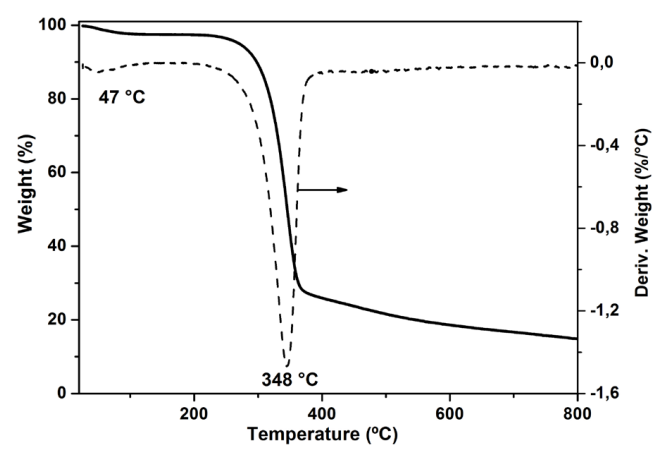

Figure 1. Thermogravimetric analysis of the cotton fiber.

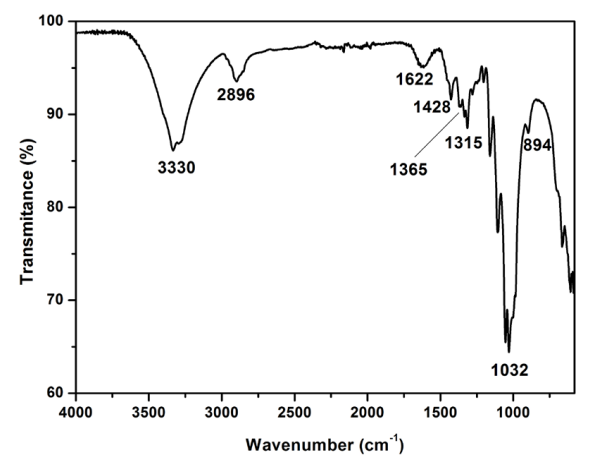

Figure 2. ATR-FTIR spectrum of the cotton fiber. 
characteristic of the hydroxyl $(\mathrm{OH})$ groups of cellulose, lignin and water ${ }^{12}$. The peak at $2896 \mathrm{~cm}^{-1}$ is characteristic of the stretching vibration of $\mathrm{C}-\mathrm{H}$ present in cellulose and hemicellulose ${ }^{9}$, and the band at $1622 \mathrm{~cm}^{-1}$ may be related to the presence of water in the fibers ${ }^{10}$. The absence of a peak at $1730 \mathrm{~cm}^{-1}$, characteristic of the carboxyl group of hemicellulose ${ }^{11}$, corroborates the TGA results, i.e. the low content of hemicellulose in cotton.

The absorption band at $1428 \mathrm{~cm}^{-1}$ is associated with the $\mathrm{CH}_{2}$ symmetric bending of the cellulose. The absorption bands at 1360 and $1315 \mathrm{~cm}^{-1}$ are relative to bending vibrations of the $\mathrm{C}-\mathrm{H}$ and $\mathrm{C}-\mathrm{O}$ groups, respectively, of the aromatic rings in cellulose polysaccharides. Intense peak vibrations observed at $1032 \mathrm{~cm}^{-1}$ are related to the $(\mathrm{CO})$ and $(\mathrm{OH})$ stretching vibrations of the polysaccharide in cellulose. The peak at $894 \mathrm{~cm}^{-1}$ indicates the presence of $\beta$-glycosidic linkages between monosaccharides ${ }^{11,13}$.

\subsection{Mechanical characterization of the laminates}

Figure 3 shows an increase in impact strength with the glass fiber content due to the improved resistance brought by these fibers in the composites ${ }^{14}$. When hybrid composites containing the same cotton/glass fraction and different stacking sequences are compared, e.g. $[\mathrm{G} / \mathrm{C} / \overline{\mathrm{G}}] \mathrm{s}$ with $[\mathrm{C} / \mathrm{G} / \overline{\mathrm{G}}] \mathrm{s}$, and $[\mathrm{G} / \mathrm{C} / \overline{\mathrm{C}}] \mathrm{s}$ with $[\mathrm{C} / \mathrm{G} / \overline{\mathrm{C}}] \mathrm{s}$, it is clear that the composites with glass layers located away from the central axis show higher impact strength ${ }^{15}$. These results were similar to those of De Rosa et al. ${ }^{16}$, who studied hybrid laminates containing E-glass/jute/E-glass layers and reported that the initial failure occurs at the top surface of the laminate and that the layers farther from the center suffered the greatest damage. They also concluded that placing glass fibers at the surface increased flexural stiffness of the laminate and, in turn, its impact strength ${ }^{17}$.

Figure 4 shows flexural strength of the laminates. It is important to note that three-point bending contains tensile, compressive and shear components, and they all benefit from the presence of glass fibers ${ }^{14}$. Thus, as expected, flexural strength of the laminate containing only glass fiber $(\approx 145 \mathrm{MPa}$ ) was much higher than that of the pure cotton $(\approx 72 \mathrm{MPa})$.

Ahmed and Vijayarangan ${ }^{18}$ studied jute/glass laminates and concluded that arranging the glass fibers at the ends increased flexural strength compared to a laminate containing intercalated jute and glass layers, which was justified by the fact that flexural strength and stiffness are controlled by the outer layers of the composite. However, the hybrid laminates studied here showed similar flexural strength when the same reinforcement ratio was used (i.e. $[\mathrm{C} / \mathrm{G} / \overline{\mathrm{C}}] \mathrm{s}$ and $[\mathrm{G} / \mathrm{C} / \overline{\mathrm{C}}] \mathrm{s}$; $[\mathrm{C} / \mathrm{G} / \overline{\mathrm{G}}] \mathrm{s}$ and $[\mathrm{G} / \mathrm{C} / \overline{\mathrm{G}}] \mathrm{s})$. The heterogeneous character of the hand-made mats, and the consequent partially non-symmetric laminate, may have been responsible for these results.

Figure 5 shows tensile strength of the different laminates, which are very dependent on the tensile strength of the fibers ${ }^{12}$. The increase in tensile strength was primarily related to the number of glass layers in the laminate. According to Jawaid et al. ${ }^{1}$, tensile strength of E-glass fiber is within 2000-3000 MPa, and that of the cotton fiber is only $\approx 400 \mathrm{MPa}$. This explains the significant difference between strength of the pure cotton $(\approx 30 \mathrm{MPa})$ and pure glass laminates $(\approx 170 \mathrm{MPa})$.

The collection of mechanical results shown above are important to evaluate the amount of glass fiber that can be replaced by waste cotton fiber in order to tailor the properties of the final laminate.

\subsection{Dynamic mechanical characterization of the laminates}

Figure 6 shows the storage modulus ( $\mathrm{E}^{\prime}$ ) for the pure resin and the laminates. A clear increase in modulus with respect to the resin was observed for the composites, which is due to the stiff reinforcement. Similar results have

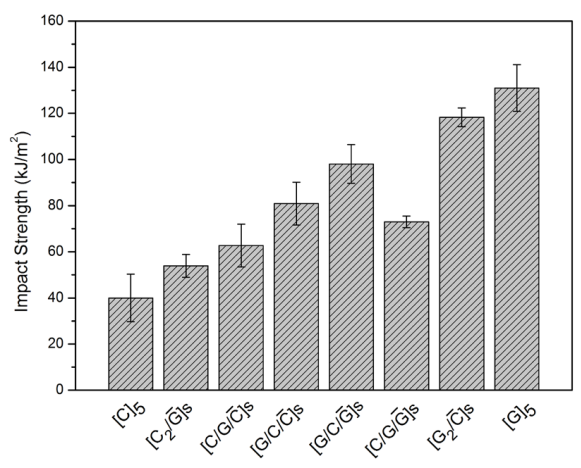

Figure 3. Impact strength of the studied laminates.

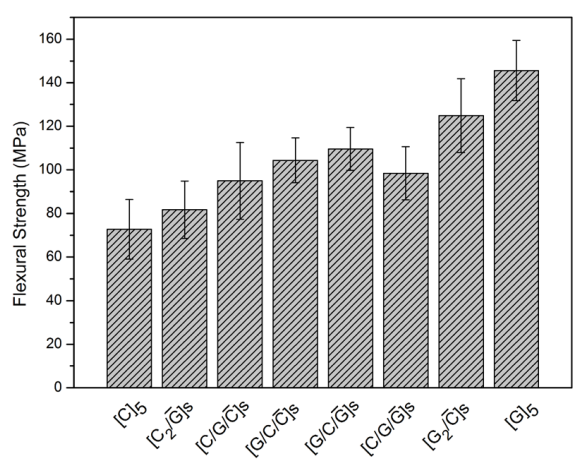

Figure 4. Flexural strength of the studied laminates.

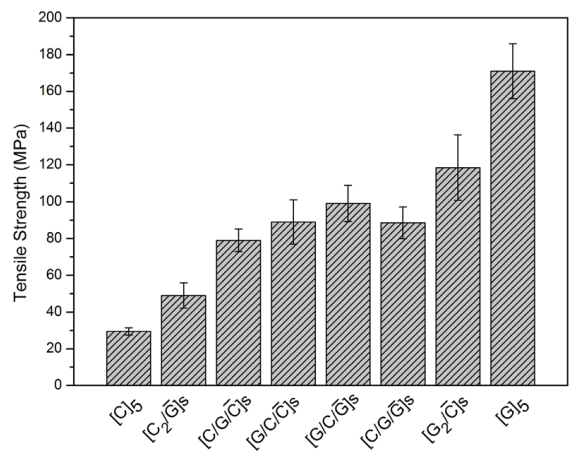

Figure 5. Tensile strength of the studied laminates. 


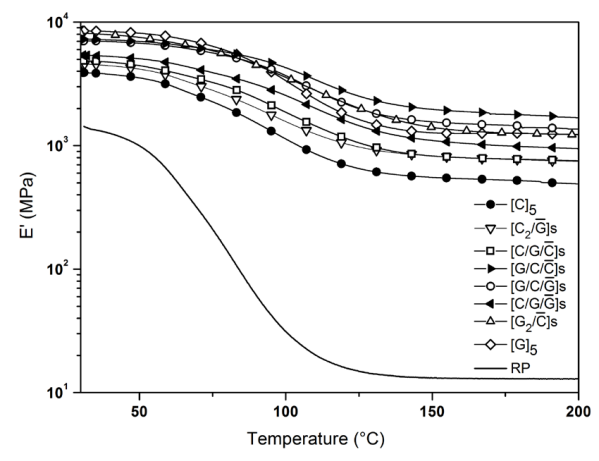

Figure 6. Storage modulus (E') curves of the resin and the laminates.

been reported for ramie-glass hybrid composites ${ }^{19}$. Also, the higher modulus of the glass fiber ${ }^{20}$ and its stronger adhesion with the polymer ${ }^{7}$, compared with cotton, lead to a greater increased in stiffness in the glassy region, for a higher glass fiber content in the laminate. This effect was more pronounced for those samples containing glass mats positioned on the ends.

As temperature, and consequently, mobility of the polymer chains increased ${ }^{7}$, modulus decreased, especially past the glass transition region. For the laminates, this reduction in modulus was less pronounced compared to the resin due to the effect of the reinforcement in the polymer matrix ${ }^{19}$. The coefficient of reinforcement effectiveness can be used to evaluate how effective the reinforcement is at maintaining the modulus as the temperature increases in comparison to the pure resin. The maximum effect occurs when the stress transfer between matrix and fiber is maximized, and low $\mathrm{C}$ values indicate greater effectiveness ${ }^{21}$, i.e. lower $\mathrm{C}$ values would be expected for the pure glass fiber laminate.

However, natural fibers and glass fibers have low coefficient of thermal expansion $(\mathrm{CTE})\left(\approx 5 \times 10^{-6} /{ }^{\circ} \mathrm{C}\right)$ compared to the polyester resin $\left(\approx 70 \pm 7 \times 10^{-6} /{ }^{\circ} \mathrm{C}\right)$. Therefore, as temperature varies, fiber and matrix will not expand or contract to the same extent, and tend to decouple due to the mismatched CTE ${ }^{22}$. Since glass fibers are treated with silanes, they are expected to resist to that effect differently from natural fibers.

In this study, similar results were found for all samples (Table 2). Previous studies ${ }^{18,23}$ for ramie/glass fiber and pineapple/glass fiber reported analogous results. These authors justified similar $\mathrm{C}$ values considering that, by increasing the volume fraction, agglomeration of glass fibers takes place, decreasing the effective fiber/matrix stress transfer.

Figure 7 shows the loss modulus (E") curves for the pure resin and the laminates. The increase in E" of the laminates compared to the resin can be explained by an increase in internal friction, with a consequent increase in dissipated energy in the system, shown by a more pronounced peak height ${ }^{24}$.

The variation in E" peak heights (Table 3) exhibited a trend similar to that of impact strength, that is, higher energy dissipation in polyester-glass compared to polyester-cotton interface. Positioning of the glass layers at the composite

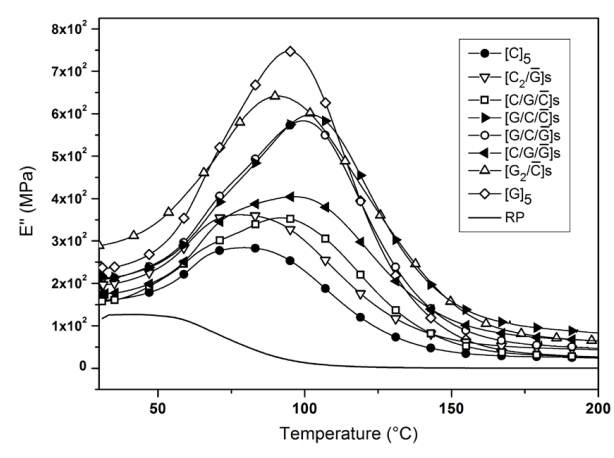

Figure 7. Loss modulus (E") curves of the resin and the laminates.

Table 2. E' (at $30^{\circ} \mathrm{C}$ ) and Effectiveness Coefficient (C) values.

\begin{tabular}{ccc}
\hline Sample & $\mathbf{E}^{\prime}(\mathbf{M P a})^{*}$ & Coefficient C \\
\hline$[\mathrm{C}]_{5}$ & 3900 & 0.07 \\
{$\left[\mathrm{C}_{2} / \overline{\mathrm{G}}\right] \mathrm{s}$} & 4570 & 0.06 \\
{$[\mathrm{C} / \mathrm{G} / \overline{\mathrm{C}}] \mathrm{s}$} & 4866 & 0.06 \\
{$[\mathrm{G} / \mathrm{C} / \overline{\mathrm{C}}] \mathrm{s}$} & 5391 & 0.05 \\
{$[\mathrm{G} / \mathrm{C} / \overline{\mathrm{G}}] \mathrm{s}$} & 7290 & 0.04 \\
{$[\mathrm{C} / \mathrm{G} / \overline{\mathrm{G}}] \mathrm{s}$} & 7057 & 0.05 \\
{$\left[\mathrm{G}_{2} / \overline{\mathrm{C}}\right] \mathrm{s}$} & 8123 & 0.06 \\
{$[\mathrm{G}]_{5}$} & 8499 & 0.07 \\
\hline
\end{tabular}

*Resin values: $\mathrm{E}^{\prime}=1417 \mathrm{MPa}$

Table 3. Peak height and Tg obtained from E" and tan delta curves.

\begin{tabular}{ccccc}
\hline \multirow{2}{*}{ Sample } & \multicolumn{2}{c}{ From E” curve } & \multicolumn{2}{c}{$\begin{array}{c}\text { From tan delta } \\
\text { curve }\end{array}$} \\
\cline { 2 - 5 } & $\begin{array}{c}\text { Peak height } \\
\text { (MPa) }\end{array}$ & $\mathbf{T}_{\mathbf{g}}\left({ }^{\circ} \mathbf{C}\right)$ & $\begin{array}{c}\text { Peak } \\
\text { height }\end{array}$ & $\mathbf{T}_{g}\left({ }^{\circ} \mathbf{C}\right)$ \\
\hline$[\mathrm{C}]_{5}$ & 172 & 83.5 & 0.15 & 103.4 \\
{$\left[\mathrm{C}_{2} / \overline{\mathrm{G}}\right] \mathrm{s}$} & 218 & 83.4 & 0.14 & 103.3 \\
{$[\mathrm{C} / \mathrm{G} / \overline{\mathrm{C}}] \mathrm{s}$} & 251 & 93.8 & 0.16 & 110.7 \\
{$[\mathrm{G} / \mathrm{C} / \overline{\mathrm{C}}] \mathrm{s}$} & 275 & 98.5 & 0.13 & 114.3 \\
{$[\mathrm{G} / \mathrm{C} / \overline{\mathrm{G}}] \mathrm{s}$} & 438 & 102.5 & 0.12 & 113.5 \\
{$[\mathrm{C} / \mathrm{G} / \overline{\mathrm{G}}] \mathrm{s}$} & 443 & 100.3 & 0.15 & 112.0 \\
{$\left[\mathrm{G} \mathrm{G}_{2} / \overline{\mathrm{C}}\right] \mathrm{s}$} & 455 & 93.1 & 0.14 & 114.5 \\
{$[\mathrm{G}]_{5}$} & 595 & 95.5 & 0.21 & 109.1 \\
\hline
\end{tabular}

Obs. Resin values: From E" (peak height $\sim 126 \mathrm{MPa}$ and $\mathrm{T}_{\mathrm{g}} \sim 50^{\circ} \mathrm{C}$ ), from tan delta curve (peak height: $0.38, \mathrm{~T}_{g} \sim 93^{\circ} \mathrm{C}$ ).

ends and increasing of the amount of glass fibers all give a positive effect in this characteristic.

Some authors suggest that it is more reliable to obtain the glass transition temperature $\left(\mathrm{T}_{\mathrm{g}}\right)$ from the loss modulus than from the tan delta peak, which tends to overestimate it $^{25}$. The $\mathrm{T}_{\mathrm{g}}$ data obtained from E" (Table 3) was higher for the $[\mathrm{G} / \mathrm{C} / \overline{\mathrm{G}}] \mathrm{s}$ laminate, followed by $[\mathrm{C} / \mathrm{G} / \overline{\mathrm{G}}] \mathrm{s}$ and $[\mathrm{G} / \mathrm{C} / \overline{\mathrm{C}}] \mathrm{s}$. These laminates also exhibited a higher $\mathrm{C}$ value. 


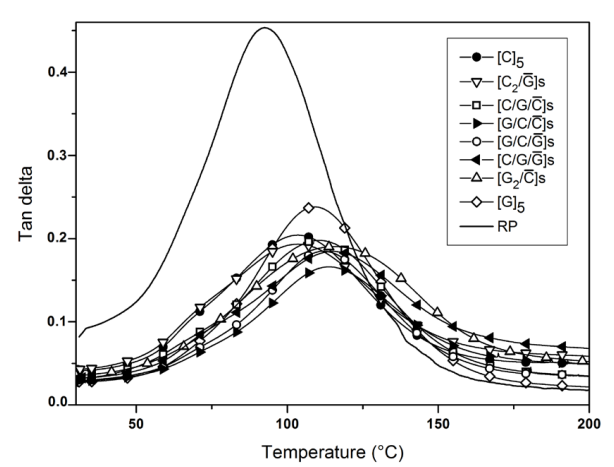

Figure 8. Tan delta curves of the resin and the laminates.

Figure 8 shows the tan delta curves for the laminates. The tan delta peak values decreased compared to the pure resin due to the hindering of polymer chains motions resulting from the incorporation of a rigid fiber. This trend is indicative of the dissipated energy related to fiber-matrix interactions at the interface, and a lower tan delta peak value suggests stronger interfacial adhesion ${ }^{26}$.

Table 3 shows the peak height values of the tan delta curves and the respective glass transition temperatures obtained for the laminates. Lower values of peak heights and higher $\mathrm{T}_{\mathrm{g}}$ values were reported for the $[\mathrm{G} / \mathrm{C} / \overline{\mathrm{C}}] \mathrm{s},[\mathrm{G} / \mathrm{C} / \overline{\mathrm{G}}] \mathrm{s}$ and $\left[\mathrm{G}_{2} / \overline{\mathrm{C}}\right] \mathrm{s}$ samples, which also exhibited the best results for $\mathrm{C}$ and loss modulus peak height.

\section{Conclusions}

Depending on the application, it is possible to partially replace the traditional glass fiber by waste cotton fiber obtained from the textile industry, in composites with unsaturated polyester. The key findings may be summarized as:

- Characterization of the cotton fiber confirmed the high cellulose and low hemicellulose/lignin content reported in the literature.

- The hybrid laminates exhibited intermediate mechanical properties between those for the pure laminates. Impact

\section{References}

1. Jawaid M, Abdul Khalil HP, Bakar AA, Hassan A, Dungani R. Effect of jute fibre loading on the mechanical and thermal properties of oil palm epoxy composites. Journal of Composite Materials. 2012;47(13):1633-1641.

2. Rahman R, Islam N, Huque M. Influence of fiber treatment on the mechanical and morphological properties of sawdust reinforced polypropylene composites. Journal of Polymer and Environmental. 2010;18(3):443-450.

3. Borsoi C, Scienza LC, Zattera AJ. Obtenção e caracterização de compósitos utilizando poliestireno como matriz e resíduos de fibra de algodão da indústria têxtil como reforço. Polímeros. 2011;21(4):271-279. http://dx.doi.org/10.1590/S010414282011005000055 tests indicated that, to ensure optimum performance, the glass fiber mats need to be at the surfaces of the composite, being this effect even more important than increasing the glass fiber content, as observed comparing the $[\mathrm{C} / \mathrm{G} / \overline{\mathrm{G}}] \mathrm{s}$ and $[\mathrm{G} / \mathrm{C} / \overline{\mathrm{C}}] \mathrm{s}$ samples.

- Impact strength followed the same trend observed for E" peak height, being both indicative of the ability to dissipate energy by the system. Flexural strength increased with the glass fiber content, especially for laminates containing glass fibers at the ends. Tensile strength was found to be mostly dependent on the relative content of each fiber.

- Storage modulus at low temperature increased with the glass fiber content. However, as the temperature increases, some hybrid laminates exhibited similar performance than pure glass laminates.

- Lower tan delta peak height values (suggesting stronger fiber-matrix interaction) and higher $\mathrm{T}_{\mathrm{g}}$ values were reported for the $[\mathrm{C} / \mathrm{G} / \overline{\mathrm{G}}] \mathrm{s}$ and the $[\mathrm{G} / \mathrm{C} / \overline{\mathrm{C}}] \mathrm{s}$ samples, which together with the $[\mathrm{G} / \mathrm{C} / \overline{\mathrm{G}}] \mathrm{s}$ sample exhibited greater reinforcement effectiveness and lower loss modulus peak height. In addition, higher $\mathrm{T}_{\mathrm{g}}$ values were found for hybrid composites instead of those with a single fiber. Perhaps, in the hybrid composites, the way the fibers are packed in the laminate may result in higher restriction imposed on the mobility of the polymer molecules at the interface.

Finally, it may be concluded that, depending on the application, composites containing waste cotton fiber may be used by tailoring the hybrid architecture (e.g. higher glass fiber fraction placed at the surface of the laminate) or considering the temperature influence (dynamic mechanical analysis), which would allow a limited amount of cotton fiber to produce similar results than pure glass fiber laminates.

\section{Acknowledgements}

The authors would like to thank Elekeiroz for providing the polyester resin, and CNPq, FAPERGS and CAPES for their financial support.

4. Romanzini D, Lavoratti A, Ornaghi Jr. HL, Amico SC, Zattera AJ. Influence of fiber content on the mechanical and dynamic mechanical properties of glass/ramie polymer composites. Materials and Design. 2013;47:9-15.

5. Khanam NP, Abdul Khalil HP, Jawaid M, Ramachandra Reddy G, Surya Narayana C, Venkata Naidu S. Sisal/carbon fibre reinforced hybrid composites: tensile, flexural and chemical resistance properties. Journal of Polymer and Environmental. 2010;18:727-733. DOI 10.1007/s10924-010-0210-3

6. Hashmi SA, Dwivedi UK, Chand N. Graphite modified cotton fibre reinforced polyester composites under sliding wear conditions. Wear. 2007;262(11):1426-1432. doi:10.1016/j. wear.2007.01.014

7. Ornaghi Jr. HL, Silva HS, Zattera AJ, Amico SC. Hybridization effect on the mechanical and dynamics mechanical properties 
of curaua composites. Materials Science and Engineering A. 2011;528(24):7285-7289. doi:10.1016/j.msea.2011.05.078

8. Pothan LA, Oommen Z, Thomas S. Dynamic mechanical analysis of banana fiber reinforced polyester composites. Composite Science and Technology. 2003;63(2):283-293. doi:10.1016/ S0266-3538(02)00254-3

9. Satyanarayana KG, Guimarães JL, Wypych F. Studies on lignocellulosic fibers of Brazil. Part I: Source, production, morphology, properties and applications. Composites Part A-Applied Science and Manufacturing. 2007;38(7):1694-1709. doi:10.1016/j.compositesa.2007.02.006

10. De Rosa IM, Kenny JM, Puglia D, Santulli C, Sarasini F. Morphological, thermal and mechanical characterization of okra (abelmoschus esculentus) fibers as potencial reinforcement in polymer composites. Composite Science and Technology. 2010; 70(1):116-122. doi:10.1016/j.compscitech.2009.09.013

11. Romanzini D, Ornaghi Jr. HL, Amico SC, Zattera AJ. Preparation and characterization of ramie-glass fiber reinforced polymer matrix hybrid composites. Materials Research. 2012;15(3):415420. http://dx.doi.org/10.1590/S1516-14392012005000050

12. Tomczak F, Satyanarayana KG, Sydenstricker TH. Studies on lignocellulosic fibers of Brazil: Part III - Morphology and properties of Brazilian curauá fibers. Composites Part A: Applied Science and Manufacturing. 2007; 38(10):2227-2236. doi:10.1016/j.compositesa.2007.06.005

13. Sgriccia N, Hawley MC, Misra M. Characterization of natural fiber surfaces and natural fiber composites. Composites Part A-Applied Science and Manufacturing. 2008; 39(10):1632-1637. doi:10.1016/j.compositesa.2008.07.007

14. Jarukumjorn K, Suppakarn N. Effect of glass fiber hybridization on properties of sisal fiber-polypropylene composites. Composite Part B-Engineering. 2009; 40(7):623-627.

15. Zang J, Chaisombat $\mathrm{K}, \mathrm{He} \mathrm{S}$, Wang $\mathrm{CH}$. Hybrid composite laminates reinforced with glass/carbon woven fabrics for lightweight load bearing structures. Materials and Design. 2012;36:75-80. DOI: 10.1016/j.matdes.2011.11.006.

16. De Rosa, IM, Santulli, C, Sarasini F, Valente M. Effect of loading-unloading cycles on impact-damaged jute/glass hybrid laminates. Polymer Composite. 2009;30(12):1879-1887. DOI: $10.1002 /$ pc.20789
17. Cantwell WJ, Morton J. The impact resistance of composite materials - a review. Composites. 1991;22:347-362.

18. Ahmed KS, Vijayarangan, SJ. Tensile, flexural and interlaminar shear properties of woven jute and jute-glass fabric reinforced polyester composites. Journal of Materials Process and Technology. 2008;207(1-3):330-335. doi:10.1016/j.jmatprotec.2008.06.038

19. Romanzini, D, Ornaghi Jr HL, Zattera A, Amico SC. Influence of fiber hybridization on the dynamic mechanical properties of glass/ramie fiber-reinforced polyester composites. Journal of Reinforced Plastic and Composite. 2012;31(23):1652-1661.

20. Nayak SK, Mohanty S, Samal SK. Influence of short bamboo/ glass fiber on the thermal, dynamic mechanical and rheological properties of polypropylene hybrid composites. Materials Science and Engineering: A. 2009;523(1-2):32-38. doi:10.1016/j. msea.2009.06.020

21. Idicula M, Malhotra SK, Joseph K, Thomas S. Dynamic mechanical analysis of randomly oriented intimately mixed short banana/sisal hybrid fibre reinforced polyester composites. Composite Science and Technology. 2005;65(7-8):1077-1087. doi:10.1016/j.compscitech.2004.10.023

22. Michell BS. An introduction to Materials Engineering and Science. New Jersey, USA: Ed. John Wiley \& Sons, 2004.

23. Devi LU, Bhagawan SS, Thomas S. Dynamic mechanical analysis of pineapple leaf/glass hybrid fiber reinforced polyester composites. Polymer Composites 2010;31(6): 956-965. DOI: $10.1002 /$ pc.20880

24. Hameed N, Sreekumar PA, Francis B, Yang W, Thomas S. Morphology, dynamic mechanical and thermal studies on poly(styrene-co-acrylonitrile) modified epoxy resin/glass fibre composites. Composites Part A:Applied Science and Manufacturing. 2007;38(12):2422-2432. doi:10.1016/j. compositesa.2007.08.009

25. Zhu J, Njuguna J, Abhyankar H, Jhu H, Perreux D, Thiebaud F, et al. Effect of fibre configurations on mechanical properties of flax/tannin composites. Industrial Crops and Products. 2013;50:68-76. doi:10.1016/j.indcrop.2013.06.033

26. Pothan LA, Oommen Z, Thomas S. Dynamic mechanical analysis of banana fiber reinforced polyester composites. Composite Science and Technology. 2003;63(2):283-293. doi:10.1016/ S0266-3538(02)00254-3 